\title{
Living Labs as Instruments for Business and Social Innovation in Rural Areas
}

\author{
Hans Schaffers ${ }^{1}$, Christian Merz ${ }^{2}$, Javier Garcia Guzman ${ }^{3}$ \\ ${ }^{1}$ Helsinki School of Economics, Fredrikinkatu 48A, FIN-00100 Helsinki, Finland, hans.schaffers@hse.fi \\ ${ }^{2}$ SAP AG, Vincenz-Priessnitz-Strasse 1, 76131 Karlsruhe, Germany, christian.merz@sap.com \\ ${ }^{3}$ Universidad Carlos III de Madrid, Avda. de la Universidad 30, 28911 Leganes, Spain, \\ jgarciag@inf.uc3m.es
}

\begin{abstract}
This paper presents results of the living labs methodology as applied to rural development. Within the C@R project, seven living labs have been launched in various regions in Europe and South-Africa. A collaborative platform has been developed to support rural communities' collaboration. The architecture of this platform is based on open service oriented architecture and allows for reusing and sharing services and applications. The paper demonstrates the validation and use of this platform, integrating various tools for various user communities, in different living labs settings. A common methodology has been designed to support the living labs launch, operation, experimentation and monitoring process. The paper presents results and evaluation of the living labs methodology. Particular focus is on the impacts of the living labs approach on the innovation process and on rural development in the different rural settings.
\end{abstract}

\section{Keywords}

Living labs, Collaboration, Systems, Innovation, Rural Development

\section{Introduction}

The C@R project (www.c-rural.eu) aims to develop and experiment a collaborative platform for enhancing working and living in rural areas. These areas are characterised by difficult conditions as regards infrastructure and socio-economic development. The living lab approach has been chosen to create environments of open and user-driven innovation and mobilise rural stakeholders, including small entrepreneurs, business associations and local policy makers. Seven rural living lab environments have been launched, in seven areas: Cudillero and Soria (both in Spain), Åboland (Finland), Frascati (Italy), Homokhátság (Hungary), Vysocina (Czech Republic), and Sekhukhune (South Africa). In all living labs, focus is on innovating current business value chains or value networks, based on concrete innovations in collaborative work environments adapted to the local context and needs of key players (Table 1).

One cornerstone of $\mathrm{C} @ \mathrm{R}$ is its collaborative platform which is still in development and testing phase. This is based on an open service-oriented architecture approach and allows the orchestration and instantiation of collaborative functions, based on a service or resource broker, for specification, development and implementation of collaborative services, tools and applications [Dörflinger et al 2008]. The other cornerstone is continuous living labs experimentation and evaluation of innovative collaborative applications and new ways of collaborative working, and embedding living labs in local innovation and rural development contexts. Our action research based approach has been to start up from the beginning of the project and grounded in local community building a series of experiments and evaluations, monitored over time, and organised in three-monthly cycles [Schaffers et al 2008]. This approach has worked remarkably well in achieving concrete results, and also provided a good basis for end-user driven software development processes. The current phase of work is to align, integrate and validate both strands of platform architecture work and living labs innovation. 


\begin{tabular}{|c|c|c|}
\hline $\begin{array}{l}\text { Rural living } \\
\text { lab }\end{array}$ & Business Value Chain Innovations & $\begin{array}{l}\text { Collaborative working } \\
\text { innovations (examples) }\end{array}$ \\
\hline Sekhukhune & $\begin{array}{l}\text { Collaborative order placement, procurement, } \\
\text { stock management, logistics }\end{array}$ & $\begin{array}{l}\text { Mobile messaging, GIS procurement, order } \\
\text { bundling, Catalogue management }\end{array}$ \\
\hline Frascati & $\begin{array}{l}\text { Business incubation support, winery } \\
\text { management }\end{array}$ & $\begin{array}{l}\text { Shared workspace, Community Blog, Single } \\
\text { Sign On }\end{array}$ \\
\hline Åboland & $\begin{array}{l}\text { Virtual council meetings, mobile direct sales in } \\
\text { tourism }\end{array}$ & Conferencing, eVoting, Calendaring \\
\hline Soria & Mycological licensing and verification & Mobile messaging, mobile GIS \\
\hline Homokhátság & $\begin{array}{l}\text { Orders and offers matching (agriculture), } \\
\text { collaborative logistics }\end{array}$ & $\begin{array}{l}\text { Collaborative workflow } \\
\text { predictions modelling }\end{array}$ \\
\hline Vysocina & $\begin{array}{l}\text { Collaborative spatial planning, Forest } \\
\text { management, Incident prevention }\end{array}$ & $\begin{array}{l}\text { Collaborative decision support and planning, } \\
\text { Map management, Conferencing }\end{array}$ \\
\hline Cudillero & $\begin{array}{l}\text { Fishery coordination (hake traceability) } \\
\text { surveillance team coordination, ship } \\
\text { communication }\end{array}$ & $\begin{array}{l}\text { Mobile messaging, presence awareness, context } \\
\text { management }\end{array}$ \\
\hline
\end{tabular}

Table 1: Focus of C@R on value chain innovations based on CWE innovations

In this paper we focus on the rural living labs innovation strand of work, and aim to summarise the results achieved so far and present some lessons learned. However, we also wish to position our work in a wider context of innovation and development theories, in order to build the bridge towards rural and regional innovation policies. In various papers [Garcia Guzman et al 2008, Schaffers et al 2008] we discussed our rural living labs innovation methodologies, and presented early results. There, we stressed the relation to action research [Baskerville 1999]. Key methodological frameworks and their relevance to C@R are summarized in Table 2. In our view these frameworks contribute to the vision of living labs as social-technical systems of innovation and to the practical role of living lab interventions in stimulating innovation and change.

\begin{tabular}{|l|l|}
\hline Methodological frameworks & Relevance C@R \\
\hline $\begin{array}{l}\text { Open service oriented architecture, } \\
\text { software architecture (not covered } \\
\text { in this paper) }\end{array}$ & $\begin{array}{l}\text { Enables the tailored orchestration and instantiation of collaborative functions } \\
\text { for development of CWEs. Enables the modularisation, reuse and sharing of } \\
\text { core services }\end{array}$ \\
\hline $\begin{array}{l}\text { National Innovation Systems } \\
\text { [Porter 1990] }\end{array}$ & $\begin{array}{l}\text { Focuses on the role of sector networking, home base advantages. Living labs } \\
\text { as rural innovation ecosystem, basis for rural development interventions. } \\
\text { Policies are part of the innovation system }\end{array}$ \\
\hline $\begin{array}{l}\text { Socio-technical systems [Lyytinen, } \\
\text { Newman 2008] }\end{array}$ & $\begin{array}{l}\text { Living lab as socio-technical system allows to focus on actors, technologies, } \\
\text { tasks and structures and their interactions, and on CWE and business } \\
\text { information systems change as underlying the innovation }\end{array}$ \\
\hline $\begin{array}{l}\text { Structuration theory [Orlikowski } \\
\text { 2000] }\end{array}$ & $\begin{array}{l}\text { Technologies are outcomes of social action, creating new structures. Focus on } \\
\text { appropriation process of technologies and on mutual shaping of technologies } \\
\text { and practices }\end{array}$ \\
\hline Action research [Baskerville 1999] & $\begin{array}{l}\text { Cycles of (joint) diagnosis, action planning, implementation, evaluation and } \\
\text { learning. Fits very well the living labs approach of open user driven } \\
\text { innovation }\end{array}$ \\
\hline Spiral development & $\begin{array}{l}\text { We have integrated action research and agile development approaches (in } \\
\text { particular SCRUM) }\end{array}$ \\
\hline
\end{tabular}

Table 2: Innovation frameworks relevance for C@R

In next sections we present and discuss some of the achievements. Section 2 evaluates the approach to creating and managing the rural living labs. Section 3 discusses selected achievements of living labs innovation and discusses rural development impacts of the living labs. Section 4 evaluates living labs as process methodology and presents conclusions. 


\section{Creating and Managing Rural Living Labs}

Our living lab approach to innovating collaborative work environments for promoting rural development has been pragmatic: it tailors the approach to the specific rural situation, in order to achieve a real socio-economic impact. Local situation determinants include the level of infrastructure and technologies, the existence of an innovation-friendly culture, and the innovation and business opportunities of interest for the particular rural area. Moreover, local characteristics include the stakeholder interests which are related to the plans and ambitions of policy makers, business associations and user organizations. Our early phase actions were aimed to ensure that these local conditions were addressed properly. It should be taken into account that besides the fact that our rural areas were very different in terms of business cases and stakeholders, most were characterized by poor economic conditions, infrastructure is lacking, ageing population and low level of innovation culture.

Table 3 summarizes the strategies chosen to develop and operate the living labs. Phasing in four major stages: 1) preparation, 2) examples prototyping and limited scale experimentation, 3) extensive application development and field experiments, 4) user-led co-creation, has proven to be a strong general approach but in need for local adaptation to needs and constraints. Building local communities to establish a stakeholder base and facilitate user involvement has not succeeded in all living labs as sometimes other instruments appeared to be more realistic and beneficial, such as stakeholder and user workshops, user focus groups and bilateral interviews. The ideal situation of early, co-creative user involvement has not been established as it took time to establish communities and getting users involved. One approach to avoid this situation could have been to establish collaborative agreements with key rural stakeholders before starting the project.

\begin{tabular}{|l|l|}
\hline $\begin{array}{l}\text { Strategies for living lab creation and } \\
\text { operation }\end{array}$ & Evaluation of the strategies in C@R \\
\hline $\begin{array}{l}\text { Phasing of living Lab launch and } \\
\text { development }\end{array}$ & $\begin{array}{l}\text { Works well, has been adopted by all living labs, but should be adapted to } \\
\text { local contexts and needs. }\end{array}$ \\
\hline $\begin{array}{l}\text { Building local communities to } \\
\text { establish a stakeholder support base } \\
\text { and involve users }\end{array}$ & $\begin{array}{l}\text { Has worked well for several living labs as platform for discussion, } \\
\text { exchange and strategy (Frascati, Aboland, Cudillero). Frascati built up a } \\
\text { workspace and portal supporting the community. }\end{array}$ \\
\hline $\begin{array}{l}\text { Agreeing on a business model for } \\
\text { open innovation partnerships }\end{array}$ & $\begin{array}{l}\text { Has worked in a few living labs and only to limited extent. However theer } \\
\text { are signs such agreements may stimulate longer term viability and } \\
\text { sustainability. }\end{array}$ \\
\hline $\begin{array}{l}\text { Creating multi-disciplinary "vertical } \\
\text { groups" to implement the living lab }\end{array}$ & $\begin{array}{l}\text { Has been a very important achievement to create multi-disciplinary teams } \\
\text { of engineers and experiment organisers including social scientists. Could } \\
\text { be further improved. }\end{array}$ \\
\hline $\begin{array}{l}\text { Run cyclic series of living lab } \\
\text { experiments, use spiral development } \\
\text { approaches }\end{array}$ & $\begin{array}{l}\text { Establishing 3-monthly cycles of innovation and evaluation, has been one } \\
\text { of the key success factors of living labs work }\end{array}$ \\
\hline $\begin{array}{l}\text { Monitor the living labs processes on } \\
\text { continuous basis during cycles }\end{array}$ & $\begin{array}{l}\text { Was very helpful in keeping the overview, gathering authentic living lab } \\
\text { and user data, and making living labs aware of processes and results }\end{array}$ \\
\hline $\begin{array}{l}\text { Capitalise on the network of seven } \\
\text { living labs to create exchanges and } \\
\text { learning }\end{array}$ & $\begin{array}{l}\text { Has been exploited to a limited extent. The collaborative platform is not } \\
\text { yet in the stage of enabling cross-living lab reuse and sharing of services. } \\
\text { Some bilateral service development and reuse activities can be identified } \\
\text { (Sekhukhone - Homokhátság, Frascati - Czech; Aboland - Cudillero). } \\
\text { However the continuous exchanges of living lab approaches and results } \\
\text { contributed to awareness and results }\end{array}$ \\
\hline
\end{tabular}

Table 3: Strategies for establishing the living lab in the rural context

Forms of open innovation agreements could be observed to emerge in several living labs although mostly in informal form e.g. collaboration plans and agreements in the Aboland, Cudillero and Frascati living labs. We are currently coaching the living labs to establish rural collaboration agreements in order to ensure longer term sustainability. 
The cyclic development iterations have been done by interdisciplinary task-forces, called vertical groups. These task-forces have been composed of end-user representatives and technical experts experienced in service oriented architecture and collaborative working environments. Several vertical groups have been established: the Spanish Vertical Group (related to Soria and Cudillero LL), the Sekhukhune-Homokhati-Aboland Vertical Group and the Czech-Italian Vertical Group. These vertical groups have had specific objectives related to support the technological needs of the living labs, specifically, developing the collaborative applications. Nevertheless, all vertical groups share the objective of defining an architectural approach to create advanced collaborative environments based on the composition of already existing basic collaboration services. In order to achieve this aim, each vertical group has been centred in different approaches and architecture implementation parts, so they are collaborating to obtain the architecture related goal. As an example, the Spanish vertical group has defined a framework to instantiate software collaboration tools specified in BPEL and managed the processes related to the orchestration and choreography of the basic collaboration services that compose an specific software collaboration tool. The Sekhukhune-Homokhati-Aboland vertical group has defined an approach for high-level modelling of software collaboration tools using Business Process Models Graphical notations that would be able to be translated as BPEL scripts. All vertical groups exchanged regularly.

A key of success to provide effective software platforms and applications to living lab end-users has been to marry agile development and the cyclic approach of action research. Agile software development methodologies implement the cyclic iterations that result into solutions based on user and system requirements. The setup of living lab experimentation allows for similar approaches as it provides the environment for continuous requirements list refinements based on explicit learning acquired in former cycles of prototypical implementation.

Finally, the networking and exchange across living labs has appeared as a decisive factor. Although not exploited to the maximum, we more and more looked at the C@R project not as a collection of seven living labs but as one living lab, experimenting in seven different settings. In these settings, different issues are experimented for example different collaboration tools, work processes and local constituencies. Across these settings it is shared a common platform architecture vision, experimentation methodologies, monitoring and evaluation approaches and also the living lab results, in order to provide a platform for understanding and learning.

\section{Key innovations achieved}

\subsection{Collaborative platform and architecture advances}

In order to enable advanced collaborative working environments a platform has been designed based on open service oriented architecture (OSOA). Key aspects are presented in [Dörflinger et al 2008]. One of the main concepts is a layered architecture design that realizes decoupled components to deal with different aggregation levels of business functionality, namely:

- Collaborative Core Services (CCS) implemented as reusable software components that encapsulate distinctive core functionality.

- Software Collaboration Tools (SCT) comprise aggregated functionality, which can be integrated into a final living labs applications, but is of such a degree of independence to be usable for various applications. Simple SCTs provide only one CCS, more sophisticated SCTs orchestrate several CCSs and OC services (for example using BPEL).

- Orchestration Capabilities (OC) provide collaborative functions and libraries to be used by executable scripts defining the composition of SCTs. Three OCs are identified, namely Context Awareness, Distributed Workspace, and Advanced Services. A Collaborative situation may involve atomic functions from different OCs such as VoIP, Messages Broadcasting, Shared Display, Videoconference systems, categorized as the three identified Orchestration Capabilities. 
- Living Lab Applications (LLA) cover end user interactions (via a user interface) with a system supporting collaborative processes aiming to overcome problems related to rural activities.

Additional to these layers a Control BUS has been conceptualized and implemented in order to centrally deal with component registration and brokerage. The architecture design provides a reference framework for the individual living labs flavoured implementations that reflect local specifics of the overall concept as a result of the contextual "engineering target point". The OSOA design comprises the following benefits that have been realized exemplary to maximize impact on end usage application level:

- Openness and Interoperability. Ensuring the interoperation amongst the different living labs, with other CWE platforms and local legacy systems via the usage of Open Standards.

- Service orientation. Following SOA principles all encapsulated functionality is offered as (web) services that allow flexible and dynamic orchestration.

- Component and concept reusability. Concept and component reuse across design and runtime environment are achieved with clear governance structures in place.

- Flexibility. In terms of deployment (platform independency) and platform operation different models are supported that also take care of infrastructure impediments that often can be found in rural environments.

In order to validate the benefit claims a common architecture, a program of validation activities has been established and. The common approach ensures that the validation targets dedicated use case oriented experiments and collaborative situations with concrete lists of components to be developed (on all architectural levels) and concrete platform instantiation activities tailored to the local context of each living lab.

The overall project structure and setup is designed to support the realisation of prospective architectural benefits at its best. Application development takes place by the 3-monthly cycles that include all phases of the action research approach. In some cases agile development methodologies like SCRUM have been applied to support the cyclic progressing. The vertical group project structure enables optimized cooperation between technical staff and business domain experts. We applied certain governance rules on the virtual group level, e.g. to support a common approach in terms of architecture validation activities.

\subsection{Innovative applications at living labs sites}

According to the different business domains the individual living labs target innovations on different product and service level. This is reflected by the great variety of business functionality mostly in CCS implementations as well as by the variety of more general collaboration tools mostly in OC implementations. In order to realize one of the key prospects of the OSOA approach (the reuse of concepts and components) extensive efforts have been invested to identify overlapping use cases to subsequently co-design components supporting formal workflows in business processes and informal collaborative situations. Some examples of overlapping use cases and related functionality include the following (see also Table 2):

- Product cataloguing in mobile direct sales (Aboland) and virtual buying cooperatives (Sekhukhune).

- SMS component in GPS based catches data sending (Cudillero) and mobile direct sales (Aboland).

- Transportation optimization in agricultural prediction framework (Homakhátság) and Virtual buying cooperatives (Sekhukhune).

- Service provider offering in tourism (Homakhátság, Czech and Sekhukhune living labs). 
- Multilanguage data loading service in the SME Incubator Portal (Frascati) and GPS based catches data sending (Cudillero).

It is important to note that the $\mathrm{C} @ \mathrm{R}$ living lab methodology offers clear advantage in sensing potential synergies across such overlapping use cases that also reflect extensive end user drive and interaction. Whilst end users often express clear needs in specific use case areas local living labs interventions often still miss innovations that leverages further end user impact. A common approach in terms of methodologies and application design offers ways of fruitful co-innovation amongst the living labs leading to supplementing innovations that can further be validated with end users (push-pull interaction).

\subsection{Networking synergies across living labs, sharing technologies, methods, services}

Despite of the variety of living lab business domains ranging from fishery, retail, tourism, agriculture etc. the $\mathrm{C} @ \mathrm{R}$ project strongly focuses on mechanisms to share services and tools between the living labs. In order to enable such networking synergies, organisational and technical setups have been tailored. As a central governance instance the Reference Laboratory provides guidelines and tools to keep track of common service design, available components and to offer reuse opportunities on various exit levels:

- Shared central service repository - Composite Services (SCT, OC) are accessible by any living lab application via a web service interface. Services (CCS, SCT, OC) from other domains can be integrated into the business process due to the web service interface ensured by BUS interface compliancy.

- Central service library - Encapsulation of OC functionality as central libraries integrated into BUS deployment. Such functionality include security (e.g. Authentication, Authorization and Accounting) and advanced services (e.g. SIP based presence services)

- Standardized Modelling - The business process is represented as BPMN model and can be easily utilized and edited in any other environment.

Thereby reusability is achieved on both design time (e.g. BPMN models) and runtime level (e.g. Web Services).

\subsection{Impact on rural development}

At the current level of the rural living labs operation in C@R, we achieved promising intermediate results that enable to identify the potential added values and impacts of living labs innovation until end of project. Examples of added value are categorised and summarised in Table 4. The main categories indicating impact on rural development are: impact on the rural innovation system, impact on current rural policies, business and entrepreneurship impacts, social and individual wellbeing impacts, and impact on internationalisation. An example of a concrete business impact at the level of micro-entrepreneurs has resulted from Sekhukhune living lab. In the Spaza-orders-bread scenario, the proposed SMS-based ordering system for Spazas provides a number of advantages for all stakeholders compared to the current way of how business is conducted in rural areas. In the case where Spazas do place an order, they currently typically have to place their order for the next day during the delivery early in the morning of the current day. At this time they cannot really estimate their demand. If they would be able to still place an order in the afternoon, most of their day's business would have been completed already and they could place a more informed order for the next day. An ordering system helps to prevent situations of empty shelves at the Spaza shop.

These types of added values are also contributing to the implementation of several rural development policies in Europe. The European Policy for Rural Development for period between 2007 and 2013 are related to the following strategic areas: 
- Improvement of the competitiveness of the agricultural and forestry sector. The living lab results enclosed in the previous types are contributing to encourage the take-up and diffusion of information and communications technologies and to foster dynamic entrepreneurship in rural areas.

- Improvement of the environment countryside. The results obtained in several living labs related to collaborative decision-making process related to land management in rural areas are contributing to preserve the farmed landscape and forests and to promote territorial balance.

- Improvement of the quality of life in rural areas and diversification of the rural economy. The living labs activities and results are contributing to several key action areas considered in this group of policies, concretely putting the heart back into villages. Integrated initiatives combining diversification, business creation, investment in cultural heritage, infrastructure for local services and renovation are contributing to the improvement of both economic prospects and quality of life.

- Finally, based on practices to implement LEADER+ policies, living labs are enhancing possibilities for innovative governance through locally based, bottom-up approaches to rural development. More specifically, living labs are contributing to this set of rural development policies by building local partnership capacity, animation and promoting skills acquisition, which can help mobilize local potential, promoting private-public partnership and improving local governance.

\begin{tabular}{|c|c|}
\hline Impact categories & Impacts identified in C@R living lab rural environments (examples) \\
\hline $\begin{array}{l}\text { Impact on rural } \\
\text { innovation } \quad \text { system } \\
\text { and sectoral strength }\end{array}$ & $\begin{array}{l}\text { Improvement of ICT infrastructure availability and capacity due to enhanced attractiveness } \\
\text { of the rural area attributed to living labs. } \\
\text { Availability of wide bandwidth communications access (based on WiMAX) enhances } \\
\text { rural area attractiveness, e.g. for tourism. } \\
\text { Strengthening the industry-university cooperation in Homokhátság living lab, Frascati } \\
\text { living lab, Czech Living lab. Homokhátság: creation of a software cluster. }\end{array}$ \\
\hline $\begin{array}{l}\text { Impact on rural and } \\
\text { regional } \quad \text { policy } \\
\text { instruments }\end{array}$ & $\begin{array}{l}\text { Interlinkages of Frascati Living lab and MEGALAB regional broadband projects. } \\
\text { Impact of Aboland Living lab on regional development plans and part of economic } \\
\text { development mechanism in the region. } \\
\text { Embedding the living lab in Local Action group / Coastal Action group mechanisms } \\
\text { Cudillero). }\end{array}$ \\
\hline $\begin{array}{l}\text { Business and } \\
\text { entrepreneurship } \\
\text { impacts }\end{array}$ & $\begin{array}{l}\text { Follow-up public and privately funded projects (Homokhátság). Exploring different } \\
\text { business models of the living lab, for future sustainability. Creation of a software cluster. } \\
\text { ESA Business Incubator (EBI-Italy) has been strengthened by Frascati Living lab. Frascati } \\
\text { Living lab enabled by collaborative workspace acts as informal breeding ground of new } \\
\text { business ideas. } \\
\text { Involvement of entrepreneurs in commercial exploitation of mobile direct sales application } \\
\text { (Aboland) } \\
\text { New possibilities of businesses in different sectors under the umbrella of new markets } \\
\text { regulation (i.e. mycological sector licensing in Soria) } \\
\text { Several examples related to businesses related cost and/or time savings, i.e., piggybacking } \\
\text { on existing business backbones in Sekhukhune (Sekhukhune). }\end{array}$ \\
\hline $\begin{array}{l}\text { Improvement of } \\
\text { social and individual } \\
\text { wellbeing }\end{array}$ & $\begin{array}{l}\text { I.e, an initiative to regulate a new economical sector (i.e. mycological sector) has been } \\
\text { obtained a high consideration by different stakeholders (LAGs, organization of } \\
\text { businessmen and local and regional administration) attracting more economical resources } \\
\text { where a Living Lab is settled down. }\end{array}$ \\
\hline
\end{tabular}

Table 4: Impacts of living lab innovation on rural development indicators 


\section{Discussion and conclusions}

The overview of results presented in earlier sections demonstrates the potential of the living lab concept in terms of business and rural development impact. It also demonstrates the effort required to make the concept work, in terms of preparation, collaboration and organisation, and the need to align the implementation to local circumstances. Although C@R hasn't exploited the possibilities to the maximum - we stressed the importance of pre-project preparation in establishing local public-private partnerships that could drive innovation processes and could ensure local uptake -, we feel that living labs could play a strong role in reinforcing rural development policies.

Whereas rural living labs are mechanisms for redefining and reconstructing rural activities economic and social - they are also instruments for innovation policies or they may enrich existing policies. A clear example is regional broadband innovation policies where living labs could fulfil a natural role. On the other hand, policy development should be part of the living lab as policies are also subject to development and change and are being shaped in a context of actors and objectives. In this sense living lab innovation, resulting in enhanced CWEs and their use, comprises a socio-technical system including all actors and establishing dialogue. The process of initiating and building a living lab could also be termed a socio-technical system, as different processes and actors play their role in making crucial decisions laying the foundations. A third system is the rural development system, where again different actors and objectives can be identified. We feel that managing and actively shaping the interactions and exchanges between the three "socio-technical" systems will be critical for success of living labs.

\section{Acknowledgement}

This work has been partly funded by the European Commission through IST Project C@R: Collaboration@Rural (No. IST-2006-34921). The authors wish to acknowledge the Commission for their support and wish to acknowledge our gratitude and appreciation to $\mathrm{C} @ \mathrm{R}$ project partners contributing to developing ideas and concepts presented here.

\section{References}

Baskerville. R.: Investigating information systems with action research, Communications of the Association for Information Systems 2, Article 19, available at: http://cais.isworld.org, 1999.

Dörflinger, Jörg; Frankova, Ganna; Lucientes, Antonio; De Louw, Rudi; Navarro, Mariano; Peña, Cristina, Ralli, Carlos, Robles, Tomás: Enhancing an Open Service Oriented Architecture with Collaborative Functions for Rural Areas. In: K.-D. Thoben, K.S. Pawar, R. Goncalves (Eds), Proceedings of the 14th International Conference on Concurrent Enterprising, pp 1117-1126, 2008.

Garcia Guzman, Javier; Schaffers, Hans; Bilicki, Vilmos; Merz, Christian; Valenzuela, Monica: Living labs Fostering Open Innovation and Rural development: Methodology and Results. ”. In: K.-D. Thoben, K.S. Pawar, R. Goncalves (Eds), Proceedings 14th International Conference on Concurrent Enterprising, pp 11271134, 2008.

Lyytinen, Kalle, Newman, Mike: Explaining information systems change: a punctuated socio-technical change model. European Journal of Information Systems 17, 589-613, 2008.

Orlikowski, Wanda: Using technology and Constituting Structures" A Practice Lens for Studying Technology in Organisations. Organization Science, Vol. 11, No. 4, July-August, pp. 404-428, 2000.

Porter, Michael: The Competitive Advantage of Nations. MacMillan Press, 1990.

Schaffers, Hans; Javier Garcia Guzman, Christian Merz, “An Action Research Approach to Rural Living Labs Innovation". In: P. Cunningham and M. Cunningham (Eds), Collaboration and the Knowledge Economy: Issues, Applications, Case Studies. IOS Press, pp 617-624, 2008. 